\title{
Heart failure in Poland: Left ventricular assist device destination therapy and other challenges of interventional cardiology and cardiac surgery
}

\author{
Mariusz Kuśmierczyk ${ }^{1}$, Jacek Różański ${ }^{1}$, Michał Zembala ${ }^{2}$, Dariusz Dudek ${ }^{3,4}$, \\ Wojciech Braksator ${ }^{5}$, Tomasz Grodzicki ${ }^{6}$, Piotr Hoffman ${ }^{7}$, Jerzy Sadowski ${ }^{3,8}$, \\ Marcin Gruchała ${ }^{9}$, Jacek Legutko ${ }^{3,10}$, Piotr Siondalski ${ }^{11}$, Karol Wierzbicki ${ }^{3,8}$,
} Bogusław Kapelak ${ }^{3,8}$, Grzegorz Opolski ${ }^{12}$, Andrzej Juraszek ${ }^{1}$, Katarzyna Bondaryk ${ }^{13}$, Jacek Walczak ${ }^{14}$, Izabela Pieniążek ${ }^{14}$, Maciej Grys ${ }^{14}$, Piotr Przygodzki ${ }^{15}$

${ }^{1}$ Department of Cardiac Surgery and Transplantology, National Institute of Cardiology, Warsaw, Poland; ${ }^{2}$ Department of Cardiac Surgery Heart and Lung Transplantation and Mechanical Circulatory Support Silesian Center for Heart Diseases, Zabrze, Poland; ${ }^{3}$ Institute of Cardiology, Jagiellonian University Medical College, Krakow, Poland; ${ }^{4}$ Maria Cecilia Hospital, GVM Care and Research, Cotignola (RA), Ravenna, Italy; ${ }^{5}$ Department of Sports Cardiology and Non-invasive Cardiac Imaging, $2^{\text {nd }}$ Medical Faculty, Medical University of Warsaw, Poland; ${ }^{6}$ Department of Internal Medicine and Gerontology, Medical College, Jagiellonian University, Krakow, Poland; ${ }^{7}$ Department of Congenital Heart Disease, National Institute of Cardiology, Warsaw, Poland; ${ }^{8}$ Department of Cardiovascular Surgery and Transplantology, The John Paul II Hospital, Krakow, Poland; ${ }^{9} 1^{\text {st }}$ Department of Cardiology, Medical University of Gdansk, Poland; ${ }^{10}$ Department of Interventional Cardiology, The John Paul II Hospital, Krakow, Poland; ${ }^{11}$ Cardiac and Vascular Surgery Department, Medical University of Gdansk, Poland; ${ }^{12} 1{ }^{\text {st }}$ Chair and Department of Cardiology, Medical University of Warsaw, Poland; ${ }^{13}$ Law Office Bondaryk, Warsaw, Poland; ${ }^{14}$ Arcana Institute a Certara Company, Krakow, Poland; ${ }^{15}$ Abbott Health Economics and Reimbursement, Warsaw, Poland

\begin{abstract}
Patients with severe heart failure $(H F)$, who are not eligible for cardiac transplantation and receive optimal medical management, based mainly on the use of pharmacological treatment and devices such as resynchronization therapy (implantable cardioverter-defibrillator), achieve poor clinical outcomes and constitute a group with extremely poor prognosis. Currently, the technology used in the latest generation left ventricular assist devices (LVADs), such as the HeartMate 3, makes it possible to achieve patient survival at the level obtained by patients after heart transplantation, and they can be used not only in patients eligible for heart transplantation as a bridge to transplant, but also in those with significantly worse prognosis, who are ineligible for heart transplantation as destination therapy.

The objective of this publication is to present recommendations from experts in cardiology and cardiac surgery, supported by clinical trial results, on the use of LVADs as a destination therapy in HF patients who are not eligible for cardiac transplantation. The paper also presents the issue of cardiac transplantation and extracorporeal membrane oxygenation therapy in Poland, as well as current challenges faced by interventional cardiology and cardiac surgery in Poland. (Cardiol J 2020; 27, 6: 693-704)
\end{abstract}

Key words: heart failure, left ventricular assist device, destination therapy, extracorporeal membrane oxygenation, dilated cardiomyopathy

Address for correspondence: Dr. Izabela Pieniążek, Instytut Arcana, ul. Kuklińskiego 17, 30-720 Kraków, Poland, tel: +48 519116 861, e-mail: izabela.pieniazek@certara.com

Received: 24.08.2020 Accepted: 12.10.2020 


\section{Introduction}

The following recommendations are based on presentations and discussions that took place during the Advisory Committee meeting organized in collaboration with the 'Quo Vadis Cardiologia?' initiative. The goal was to gather the opinions of leading experts (16 experts in total) in the fields of conservative cardiology, interventional cardiology, electrophysiology, and cardiac surgery regarding aspects of the use of left ventricular assist devices (LVADs) as a destination therapy (DT) among Polish patients. In addition, the situation of transplantation procedures and the most important challenges of interventional cardiology and cardiac surgery in Poland were discussed [1].

\section{LVADs as destination therapy}

In a selected group of patients with heart failure (HF), mechanical circulatory support (MCS) may help to achieve sustained improvements in quality of life and life expectancy. While for many patients the use of MCS is still a bridge to transplant or to recovery, for those with irreversible permanent lesions, MCS is a DT due to the insufficient number of donors and increasingly improved technical solutions [2-4]. This applies primarily to patients with severe HF:

- with accompanying renal failure - high risk of dialysis after orthotopic heart transplantation;

- who are significantly overweight (over $100 \mathrm{~kg}$ ) — difficulty in obtaining a donor;

- with persistent pulmonary hypertension high risk of primary graft failure after transplantation.

Continuous-flow left ventricular assist devices (CF-LVADs) revolutionized the management of HF patients. These compact, fully implantable cardiac pumps are able to provide a significant increase in survival and improve the function and quality of life in a selected group of patients. For such a large group of people facing a high risk of short-term mortality and a small chance of heart transplantation, implantation of CF-LVADs gives the greatest hope. In patients with a CF-LVAD the annual survival rate is $82 \%$, while in patients with pulsatile flow devices it is $61 \%[5,6]$.

INTERMACS is an American registry of patients in which data on MCS are collected from mandatory submissions regarding LVAD implantations in the United States (US) and, on a voluntary basis, from some other countries or centers. The latest INTERMACS report, published in 2017, states that over 22,000 implantations of different
MCS systems have been recorded in the last decade, of which $90 \%$ are CF-LVADs. On the basis of the available data, we know today that:

- $25 \%$ of the MCS devices are implanted as a bridge to transplant;

- $24 \%$ of the MCS devices are implanted to improve the patients' clinical status to be considered as a bridge to candidacy;

- $51 \%$ of the MCS devices are implanted under DT (compared to $3.9 \%$ in 2009) [7].

Over several decades, technical development of LVADs designed for long-term support has been observed. New solutions in the field of pump drive construction, miniaturization, and materials, as well as battery life and performance were implemented. This is directly related to a significant reduction in thromboembolic complications, bleedings, and infections, which makes these devices safe for permanent use and reduces hospital admissions. We can now distinguish three LVAD generations. First-generation LVADs include HeartMate I, LionHeart, and Novacor. Secondgeneration devices are DeBakey VAD, Incor, Jarvik 2000, and HeartMate II. The third and most recent LVAD generation includes devices such as HeartWare or HeartMate 3 [8].

The two US Food and Drug Administrationapproved and CE-marked LVADs predominantly used in long-term treatment are HeartWare and HeartMate 3. HeartMate 3 replaced the previous HeartMate II (a continuous-flow line pump) [9].

Implantation of the ventricular support system is a procedure performed in patients with severe and reversible (or irreversible) heart damage, who have exhausted all alternative treatment options, i.e. no other cardiac surgery can be performed, and pharmacological treatment cannot be expected to stop further disease progression. The LVAD is implanted through a sternotomy or using a minimally invasive technique (through left-sided mini-thoracotomy combined with right-sided upper mini-thoracotomy or mini-sternotomy) and involves the implantation of a device that ensures blood circulation by pumping it out of the left ventricle and into the aorta. The procedure is performed with extracorporeal circulation or, in selected cases, without its use. Long-term LVADs are used for longer than a month. Depending on the type of device, the drive system is pneumatic or electrical.

The LVAD that will ensure the best effectiveness as a DT in patients not eligible for a heart transplant should have, above all, a very good hemocompatibility profile: 
- achieving long survival times;

- which will be free from hemocompatibilityrelated events such as a stroke, pump thrombosis, hemolysis, or other thromboembolic events (Table 1 ).

At the same time, this translates into a significant improvement in the functional status and quality of life in this group of patients.

Advances in the management of heart disease, in particular in the area of LVAD implantation, has led to the development of pulse and then continuous flow devices. The latest-generation LVADs - centrifugal with continuous flow - are fully implanted into the pericardial sac. In these devices, the rotors are magnetically levitated, which eliminates the spaces not washed by blood, which used to be the main source of thromboembolic complications. Miniaturization of the devices has improved patient quality of life and functioning outside hospital. In some groups of patients with end-stage HF, who are not candidates for orthotopic heart transplantation, but whose expected survival is $>1$ year in good functional condition, left ventricular support can be considered as a DT to reduce clinical signs indicative of the risk of rehospitalization and premature death (European Society of Cardiology [ESC] class IIa, level B recommendation). This safe, reliable, durable, and implantable mechanism supporting the function of the left ventricle is considered an effective device for DT [10]. Using LVADs is beneficial in terms of the improvement of hemodynamic parameters (consisting of an increase of ejection fraction and of cardiac index, reduction of pulmonary wedge pressure and left ventricular end-diastolic dimension) and, consequently, improvement also of clinical parameters (improvement in functional class New York Heart Association [NYHA], quality of life, prolonged life expectancy) [6].

The 2016 ESC guidelines for diagnosis and treatment of acute and chronic HF contain a list of indications for which MCS devices are implanted (Table 2) and recommendations for the use of MSC in patients with refractory HF (Table 3).

The selection of an appropriate device depends on many factors, including the expected duration of treatment, the need for correct ventricular support, and the patient's body surface area. It is very important to exclude absolute contraindications to ventricular assist device (VAD) implantation. However, each case is assessed individually, and the listed criteria are drawn up solely for reference. At times, VADs are implanted in patients who do not yet meet the above criteria [3].
Table 1. Key parameters of long-term mechanical circulatory support (LT-MCS) devices [7].

LT-MCS characteristic
Ability to generate adequate blood flow and pressure
Easy replacement of components that may fail
Easy system removal during heart transplantation
or explantation after the failing heart's function is
restored
Small size
Fully implantable and easily renewable power source
Durability
No immunogenicity
Low degree of hemolysis
Low risk of infectious complications

Hemodynamic criteria for the use of VADs include:

- cardiac index $<2 \mathrm{~L} / \mathrm{min} / \mathrm{m}^{2}$;

— systolic blood pressure (SBP) $<90 \mathrm{mmHg}$;

- pulmonary capillary wedge pressure (PCWP $>20 \mathrm{mmHg}$;

- diuresis $<20 \mathrm{~mL} / \mathrm{h}$ [11].

Patients with severe symptoms persisting for more than 2 months, despite optimal medical and implantable device therapy, and more than one of the following, are candidates for LVAD implantation:

- left ventricular ejection fraction (LVEF) $<25 \%$ and, if measured, peak oxygen $\mathrm{VO}_{2}$ $<12 \mathrm{~mL} / \mathrm{kg} / \mathrm{min}$;

$-\geq 3$ hospitalizations for HF within the last 12 months without an obvious precipitating cause;

- dependence on IV inotropic therapy;

- progressive end-organ dysfunction (worsening renal and/or liver function) due to reduced perfusion rather than inadequate ventricular filling pressure (PCWP $\geq 20 \mathrm{mmHg}$ and $\mathrm{SBP} \leq 80-90 \mathrm{mmHg}$ or cardiac index $\left.\leq 2 \mathrm{~L} / \mathrm{min} / \mathrm{m}^{2}\right)$;

- absence of severe right ventricular dysfunction, including severe tricuspid regurgitation [11].

The reference candidate for an LVAD is a patient with chronic, congestive left ventricular failure, with a history of frequent decompensation, requiring intravenous inotropic therapy (INTERMACS 3: dependent stability) at the time of qualification or in the past, with normal or slightly impaired right ventricular function. In patients with $\mathrm{HF}$ exacerbation, who require escalation of drug therapy or the use of other MCS devices (IABP or 
Table 2. Indications for mechanical circulatory support (2016 ESC Guidelines for the Diagnosis and Management of Acute and Chronic Heart Failure) [11].

\begin{tabular}{ll}
\hline Indication & \multicolumn{1}{c}{ Rationale } \\
\hline $\begin{array}{l}\text { Bridge to decision (BTD)/ } \\
\text { /bridge to bridge (BTB) }\end{array}$ & $\begin{array}{l}\text { Use of short-term MCS (e.g. ECLS or ECMO) in patients with cardiogenic shock until } \\
\text { stabilization of hemodynamics and organ perfusion, exclusion of contraindications } \\
\text { to long-term MCS (brain damage after resuscitation), and evaluation of additional } \\
\text { therapeutic options including long-term ventricular assist device therapy and heart } \\
\text { transplant } \\
\text { Use of MCS (usually LVAD) to improve end-organ function to make an ineligible } \\
\text { patient eligible for a heart transplant }\end{array}$ \\
Bridge to transplant (BTT) & $\begin{array}{l}\text { Use of MCS (LVAD or BiVAD) to keep patients who are at high risk of death alive } \\
\text { until a donor organ is available }\end{array}$ \\
Bridge to recovery (BTR) & $\begin{array}{l}\text { Use of MCS (typically LVAD) to keep patients alive until cardiac function recovers } \\
\text { sufficiently and removal of MCS is possible } \\
\text { Long-term use of MCS (LVAD) as an alternative to heart transplantation in patients } \\
\text { with end-stage heart failure ineligible for transplantation or for long-term waiting } \\
\text { for heart transplantation }\end{array}$ \\
\hline
\end{tabular}

BiVAD — biventricular assist device; ECLS - extracorporeal life support; ECMO — extracorporeal membrane oxygenation; LVAD — left ventricular assist device; MCS — mechanical circulatory support

Table 3. Recommendations for the implantation of mechanical circulatory support in patients with refractory heart failure (2016 ESC Guidelines for the Diagnosis and Management of Acute and Chronic Heart Failure) [11].

\begin{tabular}{lll}
\hline Class & Level & \multicolumn{1}{c}{ Recommendation } \\
\hline Ila & C & $\begin{array}{l}\text { LVADs should be considered in patients with end-stage HFrEF, despite optimal medical therapy } \\
\text { and device therapy, who are eligible for cardiac transplantation in order to improve symptoms, } \\
\text { and reduce the risk of heart failure hospitalization and the risk of premature death (BTT). }\end{array}$ \\
Ila & B & $\begin{array}{l}\text { LVADs should be considered in patients with end-stage HFrEF, despite optimal medical (mainly } \\
\text { ACEI or sacubitril/valsartan, beta-blockers, and MRA) and device therapy (e.g. implantable car- } \\
\text { dioverter defibrillator and/or cardiac resynchronization therapy), who are not eligible for cardiac } \\
\text { transplantation, to reduce the risk of premature death (destination therapy) }\end{array}$ \\
\hline
\end{tabular}

ACEI — angiotensin converting enzyme inhibitor; BTT — bridge to transplant; HFrEF — heart failure with reduced ejection fraction; LVADs left ventricular assist devices; MRA - mineralocorticoid receptor antagonist

ECMO; INTERMACS class 2), LVAD implantation is a life-saving method with proven efficacy and a good safety profile.

In patients with milder disease - defined by INTERMACS as groups 4-5 - LVAD implantation may be considered as a prevention of frequent hospitalizations due to HF to improve prognosis and quality of life, especially in the population of patients with contraindications for transplantation or whose expected waiting time for the organ (e.g. obese patients) is very long [12].

Contraindications for VAD implantation include:

— irreversible advanced hepatic or renal failure;

- active systemic infection;

- chronic obstructive pulmonary disease;

- disseminated cancer;
- clinically significant purpura;

- cerebrovascular disease [3].

Unfortunately, despite the use of advanced technology, LVADs are not free of defects, and their implantation may result in early and late complications.

The main complications in patients with an implanted LVAD are driveline infections occurring in about $30 \%$ of patients and, less commonly, generalized device-related infections. There may be a risk of infection at any time after implantation, but it usually occurs between week 2 and month 12 after the procedure. The infections are usually caused by Gram-positive (Staphylococcus aureus, epidermidis) or, less frequently, Gram-negative bacteria (Pseudomonas aeruginosa, Enterobacter, and Klebsiella sp.) and fungi. In individual cases 
infection may lead to the development of bacteremia, sepsis, or endocarditis. Sepsis developing in patients with MCS promotes the formation of embolisms in the central nervous system or multiple organ failure, and it is the major cause of death. Therefore, the driveline exit site requires particular care. Dressings should be changed in fully aseptic conditions (masks, sterile gloves), washed with mild antibacterial soap and sterile saline, then covered with a sterile dressing. In addition, the driveline itself should be protected from excessive movement to minimize the risk of mechanical trauma [13]. Currently, in the event of failure of antibiotic therapy, surgical driveline repositioning is effectively used to treat infection in the exit site area. Heart transplantation is the ultimate treatment option in this situation [1].

Another significant complication is gastrointestinal bleeding or bleeding into the central nervous system, which is usually more severe. On the one hand, it is associated with the use of anticoagulants (warfarin and acetylsalicylic acid), and on the other hand, with changes in the circulatory system likely caused by less physiological continuous flow in the majority of modern circulatory support systems. The incidence of this bleeding can be reduced up to two-fold through telemonitoring. Daily international normalized ratio measurement can eliminate the risk of bleeding [1].

Moreover, the risk of device dysfunction caused by the formation of blood clots, damage to the driveline, or other electromechanical causes cannot be ignored [14]. The negative effects of thrombosis and its incidence may be limited by daily monitoring of the LVAD patient via telehealth technology [1].

An example of a telehealth system is Remedizer, which is an application used to monitor patients' health with LVADs after hospitalization [15], developed in cooperation with the National Institute of Cardiology of the Primate of the Millennium Cardinal Stefan Wyszynski in Warsaw. Patients use mobile devices to independently monitor pump parameters and vital signs such as blood pressure, weight, and body temperature, as well as blood coagulability, and to control the medications intake. The data are automatically sent to the monitoring center, where the coordinating person conducts a thorough assessment of the treatment and makes decisions on medical interventions if the patient's health state causes any concern [15].

According to data from the 2017 INTERMACS report, only about $20 \%$ of patients receiving MCS did not experience serious adverse events, such as infections, bleeding, stroke, device dysfunction, or death in the 3 years of follow-up. However, the patients' quality of life significantly improved in the first 3 months. This improvement without serious adverse events is later maintained at a similar level. Paradoxically, patients receiving long-term LVAD treatment often do not agree to the proposed heart transplant, fully approving their assisted functioning. In some patients the improvement is so spectacular that the conversion from NYHA class IV to class I/II is achieved, enabling outpatient treatment with supportive care and even removal of the device [7].

\section{HeartMate 3 - third-generation LVAD}

The HeartMate (HM) 3 LVAD is the most recent third-generation pump used for long-term cardiac support in patients with severe HF, which is usually irreversible. The device is used as a bridge to transplant, which enables the patient to survive until a heart transplant is performed. It can also be used as a DT in patients with contraindications for cardiac transplantation. The HM 3 LVAD, which replaced the previous HM II axial flow pump, is smaller than the earlier pneumatic pumps and therefore easier for the surgeon to implant. It is implanted into the left ventricle of the heart and helps to support the patient's heart for a period of several weeks up to many years [5]. The HM 3 LVAD partially mimics the pulse rate, periodically increasing rotations. This is important because the natural blood flow has a pulsating character and as such determines the proper function of the endothelium of the blood vessels. Implantable circulatory support models usually provide continuous flow. This flow is thought to be responsible for distant VAD complications (e.g. hemorrhagic, thromboembolic events). That is why such high hopes are associated with the latest third-generation pumps, such as HM 3 , in which the flow rate changes every $2 \mathrm{~s}$, creating a 'pulsation' that mimics the natural blood flow in the human body. This solution contributes to the reduction of the number of complications related to the implantation or use of the device $[5,6]$.

\section{LVAD HeartMate 3 as DT in clinical trials}

The randomized clinical trial MOMENTUM 3 compared the clinical efficacy and safety of HM 3 LVAD with HM 2 LVAD in patients with severe HF. Participants were enrolled regardless of the indication for the device implantation; however, in the results analysis the data were stratified by the indication for implantation. Finally, approximately $60 \%$ of the patients who enrolled in the 
Table 4. Distribution of patients according to the indication for use of the HeartMate 3 (HM3) or the HeartMate 2 (HM2) pump in the MOMENTUM 3 study [6].

\begin{tabular}{lccc}
\hline Indication for LVAD implantation & HM3 (n= 515) & HM2 (n = 505) & Total (n = 1020) \\
\hline BTT (bridge to transplant) & $112(22 \%)$ & $120(24 \%)$ & $232(23 \%)$ \\
BTC (bridge to candidacy) & $86(17 \%)$ & $78(15 \%)$ & $164(16 \%)$ \\
1. Likely to be candidates for a heart transplant & $45(8 \%)$ & $43(9 \%)$ & $88(9 \%)$ \\
2. Moderately likely to be candidates for a heart & $32(6 \%)$ & $33(7 \%)$ & $65(6 \%)$ \\
$\quad$ transplant & $9(2 \%)$ & $2(0.3 \%)$ & $11(0.8 \%)$ \\
3. Unlikely to be candidates for a heart transplant & $317(62 \%)$ & $307(60 \%)$ & $624(61 \%)$ \\
$\begin{array}{l}\text { DT (destination therapy): patients who are ineligible } \\
\text { for a heart transplant }\end{array}$ & & & \\
\hline
\end{tabular}

LVAD - left ventricular assist device

Table 5. Comparison of the clinical effectiveness of the HeartMate 3 left ventricular assist device implanted in the destination therapy (DT) or bridge to transplant/bridge to candidacy (BTT/BTC) indication in the MOMENTUM 3 study.

\begin{tabular}{lcc}
\hline Endpoint & DT $(\mathbf{n}=\mathbf{6 2 4})$ & BTT/BTC (n = 396) \\
\hline 2-year event-free survival & $73.2 \%$ & $76.8 \%$ \\
2-year overall survival & $76.7 \%$ & $82.7 \%$ \\
Survival at 2 years free of stroke & $88.1 \%$ & $89.2 \%$ \\
Survival at 2 years free of pump thrombosis & $97.5 \%$ & $99.4 \%$ \\
\hline
\end{tabular}

MOMENTUM 3 trial had an LVAD implanted as a DT. These participants were not eligible for heart transplantation (Table 4) [6].

The primary endpoint of the MOMENTUM 3 study was a 2 -year event-free experience (a disabling stroke or reoperation to replace or remove a malfunctioning device). A disabling stroke was defined as a modified Rankin score $>3$.

Patients not eligible for a transplant, who received the HM 3 device as a DT, achieved a 2 -year event-free survival of $73.2 \%$, which was significantly higher compared to $58.7 \%$ in patients with an HM 2 device. The likelihood of an event occurrence (a disabling stroke or reoperation to replace or remove a malfunctioning device) was almost two times lower for patients implanted with an HM 3 pump than for patients implanted with an HM 2 (hazard ratio $[\mathrm{HR}]=0.61 ; 95 \%$ confidence interval [CI] $0.46-0.81 ; \mathrm{p}=0.0006)$.

The use of the HM 3 device lowered the risk of adverse events in the form of a disabling stroke or reoperation, in order to replace/remove a malfunctioning device in the population of patients not eligible for heart transplantation, who received the LVAD as a DT at a level comparable to that in the population of patients who received the device as a bridge to transplant/bridge to candidacy (BTT/BTC) $(\mathrm{HR}=0.61$ and HR $=0.62$, respectively; 95\% CI 0.40-0.94; $\mathrm{p}=$ $=0.02$ ). Similar effectiveness of the HM 3 LVAD was demonstrated in the DT and BTT/BTC populations in terms of the 2-year event-free survival, 2-year overall survival, survival at 2 years free of stroke, and survival at 2 years free of pump thrombosis (Table 5).

Although no patient included in the MOMENTUM 3 study was NYHA class I or II, as early as at 3 months post implantation of the HM 3, the functional status of $70 \%$ of patients improved and they were classified as NYHA class I or II. During the 2 years of follow-up, the percentage of patients with NYHA class I or II increased gradually and reached $80 \%$ at 2 years post implantation of the HM 3 LVAD, regardless of the indication, DT, or BTT/BTC (vs. baseline [p $<0.0001])$.

In patients with the HM3 LVAD, an improvement from baseline in the 6-minute walking test was observed, irrespective of the intended goal of LVAD use: DT or BTT/BTC ( $<0.0001)$.

The quality of life based on EQ-5D-5L VAS form improved significantly at 3 months post implantation of the HM3 LVAD (from the baseline value of 50 to 72 ) and was sustained for 2 years after pump implantation, achieving a score of 76 after implantation of the HM3 pump and at the end of the follow-up, irrespective of the intended 
goal of LVAD use: DT or BTT/BTC (vs. baseline [p $<0.0001])$.

Currently, the technology used in the HM 3 pump allows patient survival at the same level of patients after heart transplantation and enables its use not only in patients eligible for heart transplantation as a BTT, but also in patients with considerably worse prognosis, i.e. not eligible for a heart transplantation as a DT. An important point is that patients with an implanted HM 3 LVAD as DT can achieve high clinical outcomes comparable to those in the group of patients receiving such treatment as a BTT/BTC.

\section{Funding}

Obtaining public financing of DT depends on creating a separate guaranteed health service, introducing uniform criteria for qualifying the patient to obtain this benefit, and making the procedure independent of the currently financed heart transplantation service. While under the ordinance of the Minister of Health of November 12, 2015, there were no restrictions on the use of LVAD therapy as DT, and the qualification for obtaining this service by the patient still remains associated with the transplantation procedure. Therefore, it is not clear from a legal point of view whether it is necessary to evaluate the clinical condition of the patients in terms of their suitability for cardiac transplantation during the process of qualification for an LVAD implantation. The ambiguity of these legal regulations in practice discourages healthcare providers from making decisions about LVAD implantation regardless of their patients' compliance with eligibility criteria for a heart transplant.

It is necessary to separate the LVAD implantation procedure as DT from the item currently described as highly specialized services. A change in the description of this service can be performed either by changing the description of the current highly able 4 service or by creating a new, separate basket of services including only the implantation of LVADs as DT. Taking into account the available clinical data and the premises for financing public health services, the creation of a new basket of services including exclusively the implantation of LVADs as a DT is an optimal solution for the system.

\section{Polish guidelines for MCS}

In Poland, the management procedures relating to HF patients are developed by the College of Family Physicians and the Working Group on
Heart Failure of the Polish Cardiac Society. The current treatment protocol is described in the 2017 guidelines. The guidelines were developed based on the 2016 ESC recommendations, which were also adopted by the Polish Cardiac Society. The 2017 guidelines developed by the College of Family Physicians and the Polish Cardiac Society recommend the use of LVADs in treatment-resistant patients who are classified with American College of Cardiology/American Heart Association (ACC/ /AHA) stage D HF [16].

In order to change the negative statistics for HF patients in Poland, the KONS ('Comprehensive care for patients with heart failure') system has been developed. Its introduction is expected to result in improved life expectancy, a reduced number of hospitalizations, decreased sickness absence, improved quality of life, and reduced indirect costs resulting from incapacity for work and sickness absenteeism (Social Insurance Institution [ZUS]). The main goal of the undertaking is to limit the effects of HF in Poland. The scope of the intervention includes the identification of HF symptoms, then diagnostics, therapy, rehabilitation, and long-term and palliative care $[17,18]$.

\section{Eligibility criteria for patients and centers for the use of LVAD DT}

According to clinical experts, all LVADs should be implanted as DT, which means that patients with an LVAD should not undergo a heart transplant unless specific indications exist. A heart transplantation in an LVAD patient is indicated when the individual presents with right ventricular failure and device- or driveline-related infection that cannot be treated surgically and/or with antibiotics. Hearts should be reserved for patients in a younger age group [1].

Clinical experts believe that pulmonary hypertension is not an absolute contraindication to LVAD implantation (it is sometimes indicative of a good condition of the right ventricle) but is a classic contraindication for a heart transplant. In addition, the age of patients should not be a factor determining their access to an LVAD. However, increasing the age of patients qualifying to receive an LVAD without setting an age limit will result in an increasing risk of complications. The best outcomes following an LVAD pump implantation are achieved in patients in INTERMACS 3 or 4 profiles - for instance, considerable quality of life improvement is achieved. Patients with cardiomyopathy and a history of cancer are usually not eligible for cardiac transplantation. In these patients, an LVAD is the optimal solution [1]. 
LVAD therapy should be contraindicated in patients with addiction to alcohol (alcoholic cardiomyopathy) or other psychoactive substances, if they were used at least a year prior to the planned intervention. In addition, a patient with an LVAD should have support of a family member, who should be trained in using the device and advised about possible adverse events.

Experts have agreed that it is necessary to create a roadmap describing measures needed to introduce LVADs as DT in Poland, from establishing the patient eligibility criteria (eligibility algorithm), through conducting healthcare personnel training on LVAD patient care (e.g. paramedics, primary care physicians in the patient's region of residence), to preparing society and hospital wards for the increasing number of LVAD patients.

An important element of postoperative care for patients with LVADs is the treatment of devicerelated complications, which should be managed in dedicated, specialized or initial centers depending on the complication, its extent, and prognosis. Many LVAD complications (e.g. gastrointestinal bleeding, stroke) do not require treatment at an implantation center. The main complication requiring treatment at the initial center is driveline infection.

It is recommended that LVAD pump implantations be performed at a small number of experienced heart transplantation centers where all remaining cardiological technologies are also available, because this will lead to more effective patient monitoring and adverse-effect management. In Poland, these should be 5 centers participating in the heart transplant program. Increasing the number of such sites is not necessary. In Germany, even though approximately 1000 LVADs are implanted each year, the mortality rate is high (about $33 \%$ ). This is due to the fact that LVADs are implanted in over 40 centers, the majority of which do not run a heart transplant program. These centers do not perform such strict monitoring and management of adverse effects [1].

\section{Estimation of the population of patients potentially eligible for LVAD DT}

According to the 2018 map of health needs (Mapa potrzeb zdrowotnych), the incidence of $\mathrm{HF}$ in Poland is $364.1 / 100,000$, which translates into 140,000 new HF cases each year. The paper published in 2018 entitled "Comprehensive care for patients with heart failure in Poland: suggested organizational solutions" reported the number of HF patients in Poland to be 750,000 [18].
According to clinical experts, in Poland, around 200-300 LVADs should be implanted annually. This number should increase with improved LVAD availability. The newly created health service for LVAD implantation could be provided in 5 transplantation centers that would meet the criteria defined in the service description. Assuming that about $40 \mathrm{LVAD}$ implantation procedures are performed per year per center, the initial annual number of LVAD implantations can be estimated at 200 (with a gradual increase in the following years). Given the eligibility criteria for LVAD DT, it can be expected that the number of implantations with this indication will be around 100 per year in the initial period [1].

\section{The use of LVADs and the reduction} of lost patient productivity

In the group of working-age patients with LVADs, lost productivity due to the disease will be significantly reduced. Not only does LVAD implantation extend patients' lives compared to optimal medical care, but it also enables them to return to work, which is consistent with the improvement in health status demonstrated in clinical trials and expressed by the transition to lower NYHA functional classes (from NYHA III/IV to NYHA I/II). The MOMENTUM study results regarding centrifugal and axial pumps demonstrated that 12 months after LVAD implantation, the clinical status of $81 \%$ of patients indicated they were in NYHA class I or II, while the baseline percentage of these patients was $0 \%[6,19]$. The use of LVADs will have an additional positive impact on the quality of life and productivity of patients' close relatives and careers.

\section{The heart transplant procedure situation in Poland}

For many people, heart transplantation is the only effective treatment for end-stage HF. Patients can be qualified for transplantation if all treatment methods available to them have been exhausted, including pharmacological and surgical ones, and if no significant contraindications for the procedure are identified. The most common cause of severe HF, which is an indication for a heart transplantation, is coronary heart disease and dilated cardiomyopathy, resulting from an inflammatory process or another cause, which is often impossible to determine. Less frequently identified $\mathrm{HF}$ is associated with valvular, congenital, or acquired malformations and other heart diseases [20]. 
The final decision to qualify the patient for heart transplantation is made by the Heart Failure Heart Team (HFHT), which includes the following: an experienced cardiac surgeon, a transplantologist, a cardiologist, an anesthesiologist, a psychologist, a transplant coordinator, an LVAD coordinator, and a physiotherapist in the transplantation center. On the basis of the health status of the sick recipient, the qualification procedure is determined as:

- elective - patients with stable cardiovascular and respiratory status who receive conservative treatment for HF;

- emergency - patients presenting with symptoms of severe HF despite specialist inpatient treatment; indications for inclusion in this list include intravenous therapy with drugs affecting heart activity (e.g. catecholamines), MCS (IABP, LVADs/BiVADs), as well as refractory arrhythmias [20].

The rules for including patients on the POLTRANSPLANT National Waiting List are as follows: The recipient's candidacy is reported to the National Waiting List kept by the POLTRANSPLANT Organization and Coordination Center for Transplantation Issues in Warsaw, which coordinates, supervises, and manages the register of all cell, tissue, and organ transplantations in Poland. The entry is made by the Transplant Coordinator, who begins to monitor the recipient's health on an ongoing basis from the moment the recipient is added to the list with particular attention to the following:

- patient's well-being and general health;

- patient's body weight;

- patient's international normalized ratio;

- the procedure mode (elective/emergency) — if necessary, the Coordinator reports a change of the qualification mode to the POLTRANSPLANT National Waiting List and monitors the change of the qualification decision.

The recipient entered in the National Waiting List is notified in writing of the entry into the Registers of Transplantations of the Ministry of Health by the POLTRANSPLANT Organization and Coordination Center for Transplantation Issues [20].

In Poland, the number of patients awaiting a heart transplant is increasing year by year. Even though the number of heart transplants is also increasing, it is still too low in relation to the demand. In 2018, 147 heart transplants were performed, and of these, only 23 procedures were scheduled, and the remaining ones were performed as an emergency. At the same time, experts indicate that existing transplant centers have the means to perform three times as many heart transplant procedures. The number of transplant centers should not be increased because the existing ones fully satisfy the country's needs. It is estimated that a transplant center should perform at least one heart transplant per month to ensure optimal treatment outcomes. In 2018, 326 new patients were registered for a heart transplant; however, in 2018 alone, 100 patients from the list died while awaiting a new heart. At the end of 2018, the number of patients waiting for a heart transplant was 453 . Poland boasts (after the US) the highest number of hypoplastic left heart syndrome surgeries in the world. This defect results in a single ventricular heart and a possible heart transplant in the future. In total, $40 \%$ of patients with severe HF die within a year or require hospital readmission. This is a group with unmet needs for which just the use of an LVAD offers not only a chance for survival but also for a significant improvement in quality of life [1].

\section{Major challenges of interventional cardiology: cardiogenic shock and high- -risk percutaneous coronary intervention}

Poland is among Europe's leading countries when it comes to the equipment in its interventional cardiology centers. However, it is necessary to invest in the use of percutaneous circulatory support pumps (e.g. Impella) for patients with cardiogenic shock and as hemodynamic support in high-risk percutaneous coronary intervention (protected percutaneous coronary intervention).

Cardiogenic shock, despite early coronary intervention, correction of mechanical defects, and the use of inotropic agents, is still a life-threatening complication of heart disease. Impaired end-organ perfusion caused by low cardiac output, if not reversed, leads to multiple organ dysfunction and death. One of the methods of treating cardiogenic shock is the use of MCS devices [21].

There are currently several types of these devices in use. They differ in their effectiveness and mechanism of operation, and can be divided into the following:

- short-term MCS devices i.e. Impella and intraaortic balloon pump (IABP);

- extracorporeal membrane oxygenation (ECMO);

- implantable LVADs (e.g. HM3 LVAD) or biventricular assist devices,

— total artificial heart [22]. 
They differ, among other things, in the technique of insertion (percutaneous or surgical), the influence on individual heart structures (support of the left, right, or both ventricles), and in terms of the possibility of combined use with ECMO [22].

The 2018 ESC/EACTS guidelines on myocardial revascularization list the following short-term MCS devices:

- percutaneous LVAD;

- veno-arterial ECMO;

- IABP, which may have a beneficial effect on some hemodynamic parameters, but does not improve survival; therefore, the routine use of IABPs in patients with cardiogenic shock complicating acute myocardial infarction is not recommended [23].

\section{ECMO}

Interventions performed to decrease left ventricular workload include the following:

- percutaneous - Impella (possible vascular complications due to access route);

- surgical - ECMO:

- intermediate-term cardiac and respiratory support or respiratory support alone,

- can be used in a broad range of patients,

- percutaneous and direct implantation [1].

ECMO involves the use of extracorporeal circulation based on a modern centrifugal pump to oxygenate blood and eliminate carbon dioxide in the oxygenator. Extracorporeal circulation makes it possible to adjust the blood flow rate and accurately control its temperature. Blood is transported to and from the ECMO machine using a plastic cannula system. To reduce the risk of blood clot formation during ECMO, adequate anticoagulation is required with unfractionated heparin and activated partial thromboplastin time kept between 45 and 60 seconds [24].

Depending on the underlying disease and the expected effect, two main ECMO circuit configurations are used:

- veno-venous (VV), in which a cannula is placed into the jugular and/or femoral vein, or a special dual-lumen cannula is inserted into the jugular vein. This set-up is used in cases of severe respiratory failure without circulatory dysfunction when the option of mechanical ventilation has been exhausted. The primary goal of this therapy is to provide the body with oxygen and eliminate carbon dioxide. Oxygen- ated blood from the oxygenator is transported back to the venous system and then through the right ventricular myocardium to the lungs, left atrium, left ventricle, and aorta;

- veno-arterial (VA), which involves placing a venous cannula in the jugular and/or femoral vein and an arterial cannula in the femoral artery, ascending aorta, or subclavian artery. This type of vascular cannulation is used in cases of circulatory failure or concomitant cardiopulmonary dysfunction. If the decision to use ECMO during cardiac surgery is made, the cannulation can be performed directly through the chest (most often with cannulae placed in the right atrium and ascending aorta) - this is called central cannulation. The inflow of oxygenated blood to the arterial system with adequate kinetic energy generated by the ECMO pump supports the blood flow that the myocardium cannot provide [24].

In cases of respiratory failure, VV ECMO is used primarily in patients with severe pneumonia and acute respiratory distress syndrome. Indications for VA ECMO include the following:

- post cardiotomy;

- shock in post-coronary artery bypass grafting patients;

- post-myocardial infarction VSD;

- de novo cardiogenic shock;

- HF exacerbation;

- primary graft dysfunction;

- heart transplant rejection [1].

Experience with ECMO at the Institute of Cardiology in Warsaw:

- from 2013 to the end of 2019, mainly VA ECMO: $\mathrm{n}=300$ implantations $(2013, \mathrm{n}=25$ $\rightarrow 2018, \mathrm{n}=63$ );

- $\mathrm{N}=133$ deaths on ECMO (55.6\%) (2013: 15 deaths [60\%] $\rightarrow$ 2018: 21 deaths [33.34\%]).

ECMO in interventional cardiology is a universal tool because it can provide support during percutaneous coronary intervention and in cases of cardiogenic shock; in addition, it can be used simultaneously with IABP. Moreover, ECMO is an effective strategy for stabilizing critically ill patients as a bridge to long-term MCS. A 2019 retrospective study demonstrated that in patients on ECMO support as a bridge to HM3 LVAD, survival to discharge was $81 \%$ [25]. The combined use of ECMO and Impella is also promising. When this system is used, Impella ensures additional left ventricle unloading, optimizing ECMO operation [26]. 


\section{Conclusions}

Patients with severe HF, especially those in NYHA class III/IV, who present with concomitant diseases that preclude their qualification for a heart transplant, are a group with unmet needs in terms of survival, and they have poor functional status, various mobility limitations, and associated significantly reduced quality of life. Current optimal medical care provided with the use of pharmacological agents and medical devices such as implantable cardioverter-defibrillator and IABP is not enough to fulfil these needs. MCS based on LVAD DT is an alternative option for this patient population. The LVAD that will achieve the best clinical effectiveness as DT in this group of patients should be characterized above all by a very good hemocompatibility profile that will allow for long survival, free of events related to hemocompatibility, such as stroke, pump thrombosis, hemolysis, or other thromboembolic events. At the same time, this translates into a significant improvement in functional status and quality of life.

LVAD HM3 has all of the above-mentioned features of optimal DT in patients with severe HF, who do not qualify for a heart transplant. Its use enables patients to achieve significantly longer survival than with optimal medical management. In addition, the device meets the patients' needs in terms of significantly improved functional status and quality of life. Positive outcomes achieved in patients not qualified for heart transplantation, who received the HM3 LVAD, are comparable with those in individuals qualifying for a heart transplant, who underwent HM3 implantation as a BTT/BTC. Technological progress and innovative technological solutions applied in the HM3 LVAD allow for a 2-year overall survival comparable to that achieved in patients with a heart transplant.

In a paper published in 2019, leading Polish experts in the field of cardiology and cardiac surgery indicated that the use of the HM3 LVAD would contribute to the improvement of patient survival, health-related quality of life, reduction of treatment costs, and limitation of the number of adverse cardiovascular events. They also indicated that in Poland, pump implantation and heart transplantation are included in the same healthcare service. Therefore, there is no procedure available that would cover the costs of hospitalization following a ventricular assist device implantation. It was emphasized that one of the measures that should be developed in order to increase patient access to HM3 technology is a public funding system appropriate for this purpose [5].

Moreover, experts have indicated that currently the number of LVAD procedures, especially LVAD DT, is very limited. One of the reasons for this is excessively restrictive inclusion criteria and the lack of a separate service dedicated to LVAD DT. Experts recommend that the implantation of LVADs should be carried out in several Polish centers experienced in heart transplantations, because this will lead to more effective patient monitoring and adverse effect management.

\section{Conflict of interest: None declared}

\section{References}

1. Advisory Board Meeting 'Quo Vadis Cardiologia': Innovation $\&$ Health Economics Poland (HF/CMD).

2. Sobieszczańska-Małek M. Mechaniczne wspomaganie: czy tylko pomost do przeszczepu serca? Kardiol Pol. 2012; 70(11): 1182-1186.

3. Bielecka A. Urządzenia wspomagające pracę komór: leczenie pomostowe do momentu uzyskania ponownej wydolności komory lub do czasu przeszczepu oraz leczenie docelowe. Folia Cardiologica Excerpta. 2007; 2(2): 54-64.

4. Michalak M. Inwazyjne leczenie niewydolności serca. Choroby Serca i Naczyń. 2014; 11(1): 47-50.

5. Dudek D, Banasiak W, Braksator W, et al. Recommendations on the use of innovative medical technologies in cardiology and cardiac surgery and solutions leading to increased availability for Polish patients. Cardiol J. 2019; 26(2): 114-129, doi: 10.5603/ CJ.a2019.0007, indexed in Pubmed: 30761517.

6. Mehra MR, Uriel N, Naka Y, et al. MOMENTUM 3 Investigators. A fully magnetically levitated left ventricular assist device — final report. N Engl J Med. 2019; 380(17): 1618-1627, doi: 10.1056/NEJMoa1900486, indexed in Pubmed: 30883052.

7. Pinney SP. Left ventricular assist devices for lifelong support. J Am Coll Cardiol. 2017; 69(23): 2845-2861.

8. Starska A. Nowości w mechanicznym wspomaganiu krążenia. Kardiologia Inwazyjna. 2013; 8(4).

9. Zieliński T. Wspomaganie lewokomorowe - metoda o rosnącym znaczeniu w leczeniu zaawansowanej niewydolności serca. Kardiologia po Dyplomie. 2018: 03.

10. Mehra MR. Evolving disruption in left ventricular assist systems: forgiving but not yet forgettable. Eur J Heart Fail. 2019; 21(1): 98-100, doi: 10.1002/ejhf.1340, indexed in Pubmed: 30508266.

11. Ponikowski P, Voors AA, Anker SD. Wytyczne ESC dotyczące diagnostyki i leczenia ostrej i przewlekłej niewydolności serca w 2016 roku, Grupa Robocza Europejskiego Towarzystwa Kardiologicznego (ESC) do spraw diagnostyki i leczenia ostrej i przewlekłej niewydolności serca. Kardiol Pol. 2016; 74(10): 1037-1147, doi: 10.5603/KP.2016.0141.

12. Rubiś P. U których pacjentów $z$ niewydolnością serca należy rozważyć wszczepienie urządzenia wspomagającego czynność lewej komory? Medycyna Praktyczna Kardiologia. 2018. 
13. Han J, Trumble DR. Cardiac assist devices: early concepts, current technologies, and future innovations. Bioengineering (Basel). 2019; 6(1), doi: 10.3390/bioengineering6010018, indexed in Pubmed: 30781387.

14. Sterczyński R. Mechaniczne wspomaganie krążenia oddala przeszczep serca. Medical Tribune. 2016.

15. Szymanski J, Juraszek A, Jasińska M, et al. REMEDIZER- An Innovative Program of Remote Home Care for Patients with Implanted Mechanical Heart Support. Single Centre Experience. J Heart Lung Transplantation. 2019; 38(4): S461-S462, doi: 10.1016/j.healun.2019.01.1176.

16. Nessler J. Projekt programu kompleksowej opieki nad chorymi z niewydolnością serca (KONS). Kardiologia Inwazyjna. 2018; 13(6): $10-17$.

17. Gierczyński J, Priorytety zdrowotne w kontekście demograficznego i gospodarczego rozwoju Polski. Wnioski i rekomendacje na przykładzie niewydolności serca. Raport Warsaw Enterprise Institute. Warsaw, 2018.

18. Nessler J. Kompleksowa opieka nad chorymi z niewydolnością serca w Polsce: propozycje rozwiązań organizacyjnych. Kardiol Pol. 2018; 76(2): 479

19. Goldstein D, Naka Y, Horstmanshof D, et al. Association of clinical outcomes with left ventricular assist device use by bridge to transplant or destination therapy intent. JAMA Cardiology. 2020; 5(4): 411, doi: 10.1001/jamacardio.2019.5323.
20. W oczekiwaniu na przeszczep serca. Poradnik informacyjno edukacyjny dla Pacjenta i jego Bliskich. Fundacja Śląskiego Centrum Chorób Serca. 2013

21. Lamarche $\mathrm{Y}$, Cheung A, Ignaszewski A, et al. Comparative outcomes in cardiogenic shock patients managed with Impella microaxial pump or extracorporeal life support. J Thorac Cardiovasc Surg. 2011; 142(1): 60-65, doi: 10.1016/j.jtcvs.2010.07.075, indexed in Pubmed: 20880553.

22. Drabik A. Mechaniczne wspomaganie rzutu serca. Przegląd metod i urządzeń. Inżynier i Fizyk Medyczny. 2017; 6: 57-60.

23. Neumann FJ, Sousa-Uva M, Alfonso F, et al. Wytyczne ESC/ /EACTS dotyczące rewaskularyzacji mięśnia sercowego. Kardiol Pol. 2018; 76(12): 1585-1664, doi: 10.5603/KP.2018.0228.

24. Arendarczyk A, Wilimski R, Michniewicz M, et al. Zasady kwalifikacji do ECMO u osób dorosłych. Folia Cardiologica. 2017; 12(1): 113-117, doi: 10.5603/fc.2017.0016.

25. Ayers BC, Sagebin F, Wood K, et al. Extracorporeal Membrane Oxygenation is an Effective Bridge to Left Ventricular Assist Device Implantation. J Heart Lung Transplantation. 2019; 38(4): S436-S437, doi: 10.1016/j.healun.2019.01.1113.

26. Tschöpe C, Van Linthout S, Klein O, et al. Mechanical Unloading by Fulminant Myocarditis: LV-IMPELLA, ECMELLA, BI-PELLA, and PROPELLA Concepts. J Cardiovasc Transl Res. 2019; 12(2): 116-123, doi: 10.1007/s12265-018-9820-2, indexed in Pubmed: 30084076 . 